\title{
TRANSFORMAÇÕES DO USO DA TERRA NO MUNUCÍPIO DE MUNHOZ DE MELLO - PARANÁ, COM ÊNFASE NA RECOMPOSIÇÃO DA COBERTURA FLORESTAL ENTRE OS ANOS DE 2006 E 2016.
}

\author{
Lourenço José Neto Moreira ${ }^{1}$ \\ Maria Eugênia Moreira Costa Ferreira²
}

Resumo: Este trabalho tem como objetivo analisar as mudanças na paisagem florestal do município de Munhoz de Mello-Paraná, Brasil, permitindo avaliar o aumento das Áreas de Preservação Permanente, por meio dos mapas de uso da terra, no período que correspondeu entre os anos de 2006 e 2016. Para a elaboração dos mapas de Uso da Terra e Vegetação, foram utilizadas a Base cartográfica do IBGE (2010), imagens de satélite LandSat 5, sensor -TM (2006) e LandSat 8 (2016). As imagens foram manipuladas no software ArcGis versão 10.4.1. O mapeamento permitiu analisar a distribuição dos diferentes usos, constituindo-se como um importante subsídio para a interpretação das mudanças na paisagem, tanto no que se refere ao quadro natural, como na ocupação e organização do território. Os resultados mostraram que houve um pequeno aumento na área ocupada pela cultura temporária, passando de $67,9 \%$ em 2006 para 68,7\% em 2016. Nas áreas destinadas à pastagem ocorreu um decréscimo de $29,1 \%$ para $25,5 \%$ no mesmo período e no que se refere à vegetação densa/mata presente principalmente nas Áreas de Preservação Permanente houve um aumento de 2,1\% em 2006 para 4,3\% em 2016.

Palavras-chave: Paisagem florestal; uso da terra; organização do território; Áreas de Preservação Permanente.

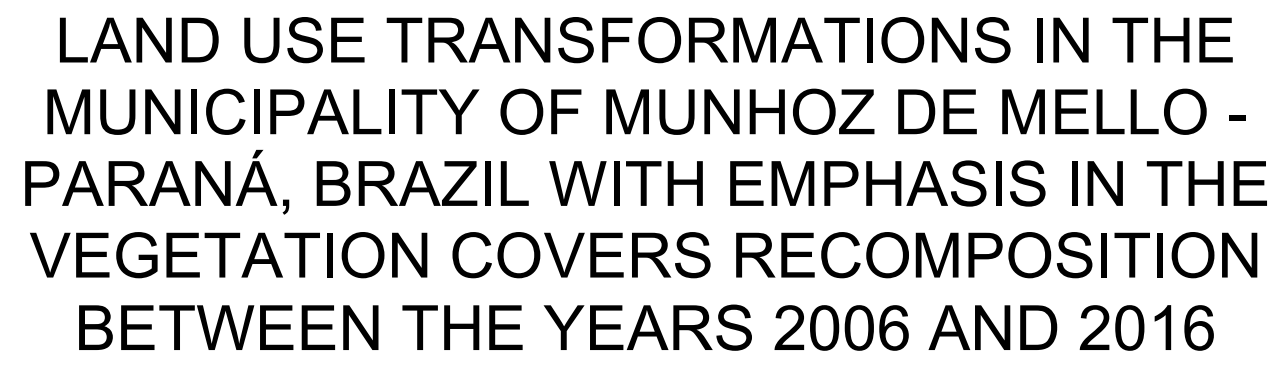

Abstract: This study aimed to analyze the changes in the forest landscape of the municipality of Munhoz de Mello - Paraná, Brazil, allowing evaluating the Permanent Preservation Areas increase, through land use maps, in the corresponding period between the years 2006 and 2016. The IBGE

\footnotetext{
${ }^{1}$ Doutorando em Geografia pela UEM. lourencojose81@gmail.com

2 Profa. Dra . do Departamento de Geografia e do Programa de Pós-Graduação em Geografia da UEM. eugeniaguart@gmail.com
} 
cartographic base (2010), LandSat 5 satellite images, sensor-TM (2006) and LandSat 8 (2016) were used for the elaboration of Land Use and Vegetation maps. The images were manipulated in ArcGis 10.4.1 software. The mapping allowed to analyzing the different uses distribution, constituting an important subsidy for the interpretation of the landscape changes, both with regard to the natural picture, and in the occupation and organization of the territory. The results showed that there was a small increase in the area occupied by the temporary crop, going from $67.9 \%$ in 2006 to $68.7 \%$ in 2016 . The pasture areas declined from $29.1 \%$ to $25.5 \%$ in the same period and as regards dense vegetation/forest, present mainly in the Permanent Preservation Areas, there was an increase of $2.1 \%$ in 2006 to $4.3 \%$ in 2016.

Keywords: Forest landscape; land use; territory organization; Permanent Preservation Areas.

\section{INTRODUÇÃO}

A dinâmica de ocupação da terra pode ser compreendida a partir da interpretação dos elementos presentes em uma paisagem, neste sentido o trabalho teve como objetivo compreender as transformações da paisagem florestal do município de Munhoz de Mello, Paraná. Por meio da análise dos fragmentos florestais em um período que correspondeu entre os anos $2006 \mathrm{e}$ 2016, onde é possível evidenciar as transformações antrópicas, identificadas pelas formas de uso e ocupação, como elementos responsáveis pela organização do espaço e transformação da paisagem.

O processo de ocupação da região Norte Central Paranaense foi marcado por rápidas mudanças, influenciadas principalmente pelo seu potencial ecológico, por oferecer extensas áreas recobertas por solos com grande potencial produtivo, relevo sem grandes limitações de uso, densa floresta (que serviu de matéria prima das primeiras habitações), grande riqueza hídrica; todos esses elementos favoreceram 0 desenvolvimento do empreendimento imobiliário no meio rural e no meio urbano, que se estabeleceu na região Norte Central Paranaense.

Nesta pesquisa, a paisagem é tratada como elemento de análise, na perspectiva de considerar os diferentes elementos que a compõem, aspectos naturais e socioeconômicos, que juntos contribuem para a transformação dela.

Com relação à cobertura vegetal, a expansão do uso e ocupação da terra, pela agricultura e pecuária, constituíram elementos responsáveis pela transformação da paisagem florestal, favorecendo o desmatamento e a fragmentação florestal, ficando estas circundadas por áreas destinadas a pastagem e a agricultura.

Inicialmente a cultura cafeeira se constituiu como carro chefe da atividade econômica na região. Mas em decorrência das políticas de erradicação do café para estabelecimento de um modelo agrícola moderno e mecanizado, a partir da década de 70 do século XX, passa a expandir as áreas destinadas às lavouras temporárias de soja, trigo, milho e posteriormente a cana-de-açúcar.

Ribeiro Junior e Paiva (2013), analisando as transformações da paisagem, descreveram a dinâmica de expansão das culturas modernas 
soja/trigo e/ou soja/milho, cultivadas nas áreas de basalto com solos mais argilosos, e de pastagens plantadas e algumas culturas anuais como a canade-açúcar, cultivadas nas áreas de substrato arenítico com predomínio de solos de textura média.

\section{ANÁLISE DO USO DA TERRA COMO ELEMENTO NA COMPREENSÃO DA DINÂMICA DA PAISAGEM}

A dinâmica de ocupação da terra pode ser compreendida a partir da interpretação dos elementos presentes em uma paisagem, como a ocorrência do desmatamento e as mudanças na agricultura e na pecuária. Neste sentido, a análise do Uso da Terra que "consiste em buscar conhecimento de toda a sua utilização por parte do homem, ou quando não utilizado pelo homem" (RESENDE et. al. 2011. p. 6955), constitui uma possibilidade de avaliar os danos ambientais e possíveis formas de recuperação.

Com o avanço e incorporação das técnicas de sensoriamento remoto, houve importante mudança nas formas de interpretação da paisagem, possibilitando avaliar historicamente as mudanças nas formas de ocupação, o comportamento espacial da paisagem, como o desmatamento, a fragmentação florestal e a recomposição dos remanescentes florestais.

Com a incorporação de técnicas de sensoriamento remoto para a interpretação analógica de fotografias aéreas e imagens na identificação de padrões de uso da terra, inicia-se uma nova fase, na qual o avanço da tecnologia espacial, com as técnicas de geoprocessamento, caracterizou o momento da disponibilidade de produtos de satélites imageadores da terra como marco de uma nova era dos estudos de Uso da Terra, pois ao mesmo tempo que lhe dá uma nova metodologia de pesquisa, revela a concepção teórica que orienta a apreensão espacial e temporal do uso da terra no seu conjunto para a gestão da apropriação do espaço geográfico global ou local. (IBGE, 2013.p.27).

A utilização das informações obtidas a partir da produção cartográfica do Uso da Terra passa a constituir uma importante ferramenta de conhecimento sobre as mudanças espaciais e temporais, assim os levantamentos podem indicar os padrões homogêneos da cobertura terrestre, sejam estes apresentados pela utilização agrícola ou pela natureza.

Este método "envolve pesquisas de escritório e de campo, voltadas para a interpretação, análise e registro de observações da paisagem, concernentes aos tipos de uso e cobertura da terra, visando sua classificação e espacialização por meio de cartas" (IBGE, 2013.p.36).

O levantamento sobre a Cobertura e o Uso da Terra comporta análises e mapeamentos e é de grande utilidade para o conhecimento atualizado das formas de uso e de ocupação do espaço, constituindo importante ferramenta de planejamento e de orientação à tomada de decisão (IBGE, 2013.p.37). 
A respeito do mapeamento do Uso da Terra e Cobertura Vegetal Natural, Brito e Prudente (2005) salientam a importância do mapeamento em uma dada região, para a compreensão da organização do espaço e das mudanças ocorridas, uma vez que o meio ambiente está em constante transformação.

Sobre o Uso da Terra, Pereira e Pinto (2007, p. 1321) citam que "seu estudo consiste em buscar conhecimento sobre a utilização das terras, além de caracterizar as diferentes classes vegetais que compõem a área", auxiliando na interpretação das mudanças no quadro natural e ocupação territorial.

\begin{abstract}
A velocidade e extensão com que problemas ambientais vêm ocorrendo, decorrente da intensa pressão gerada pela ocupação antrópica, exige-se a utilização de técnicas de coleta de dados e de monitoramento sistemático da superfície terrestre, compatíveis com rapidez destas mudanças[...] as técnicas de sensoriamento remoto têm-se mostrado instrumentos de vital importância aos estudos desta temática, uma vez que permitem, com melhores resultados, os levantamentos, análises e monitoramento de elementos do meio físico terrestre. (PEREIRA; PINTO, 2007, p.1322).
\end{abstract}

Neste sentido, vários trabalhos passaram a ser desenvolvidos sobre essa temática, com intenção de propor métodos e técnicas do uso do sensoriamento remoto para a elaboração de mapas temáticos e a respeito do Uso da Terra, sobretudo, com o intuito de avaliar os aspectos relacionados ao meio ambiente e as relações socioeconômicas.

\title{
METODOLOGIA
}

Por meio de levantamentos de séries históricas de imagens como as do Landsat foi possível avaliar o processo em que se deu as mudanças do Uso da Terra, o desmatamento e a recomposição florestal no município de Munhoz de Mello - PR, evidenciadas pela transição da cultura permanente para a agricultura temporária e o recuo da atividade pecuária.

Os estudos pautados na análise do Uso da Terra e Cobertura Vegetal mostraram-se importantes ferramentas aplicadas na gestão do território, no desenvolvimento de ações de recuperação da fauna e flora.

Para a elaboração dos mapas de Uso da Terra e Vegetação, foram utilizadas a Base cartográfica do IBGE (2010), imagens de satélite LandSat 5, sensor -TM ( 2006) e LandSat 8 (2016), sensor - OLI, correspondentes à órbita 222 e ponto 76, com resolução espacial de 30 metros, já processadas (georreferenciadas), obtidas via sitio eletrônico do U.S Geological Survey (USGS - GLOVIS). As imagens foram trabalhadas no software ArcGis versão 10.4.1 (free trial), onde foram procedidos os seguintes passos: composição das bandas (4, 5 e 6 - LandSat 2; 1, 2 e 3 - LandSat 5 e 2, 3 e 4 - LandSat 8) na extensão Image Analisys - Composite Bands, aplicação da composição colorida (RGB - falsa cor) e recorte da cena de interesse utilizando a extensão Spatial Analist Tools - Extraction - Extract by Mask. O processamento, das imagens foram submetidas à interpretação, segundo sua forma, textura e cor dos objetos amostrados. Nessa etapa foram estipuladas cerca de 30 parcelas de treinamento por tipo de uso identificado; esse processo foi realizado utilizando a extensão Image Classification - Training Sample Manager. As 
parcelas de treinamento foram divididas em seis grupos de tipos de uso da terra, que são representados por:

I. Vegetação Densa/Mata

II. Silvicultura (cultivo de eucalipto e pinus);

III. Cultivos Permanentes (cultivo de laranja e café);

IV. Cultivos Temporários (cultivo de cana-de-açúcar, soja, milho e trigo);

V. Pastagem (pastos e vegetação de brejo);

VI. Áreas Urbanas.

A classificação da imagem foi procedida utilizando o método supervisionado MAXVER (Máxima Verossimilhança). Segundo Florenzano (2002), esse método de classificação utilizado é caracterizado como do tipo "pixel a pixel" porque utiliza apenas a informação espectral, isoladamente, de cada pixel para encontrar regiões homogêneas. Este algoritmo considera a ponderação das distâncias entre médias dos níveis digitais das classes, utilizando parâmetros estatísticos. Posteriormente à classificação, a imagem resultante foi submetida ao filtro de pós-classificação da extensão Spatial Analist Tools - Generation -Majority Filter para diminuir os erros de identificação de cada pixel.

\section{CARACTERIZAÇÃO DA ÁREA DE ESTUDO}

\section{Figura 1- Localização do município de Munhoz de Mello - Paraná}

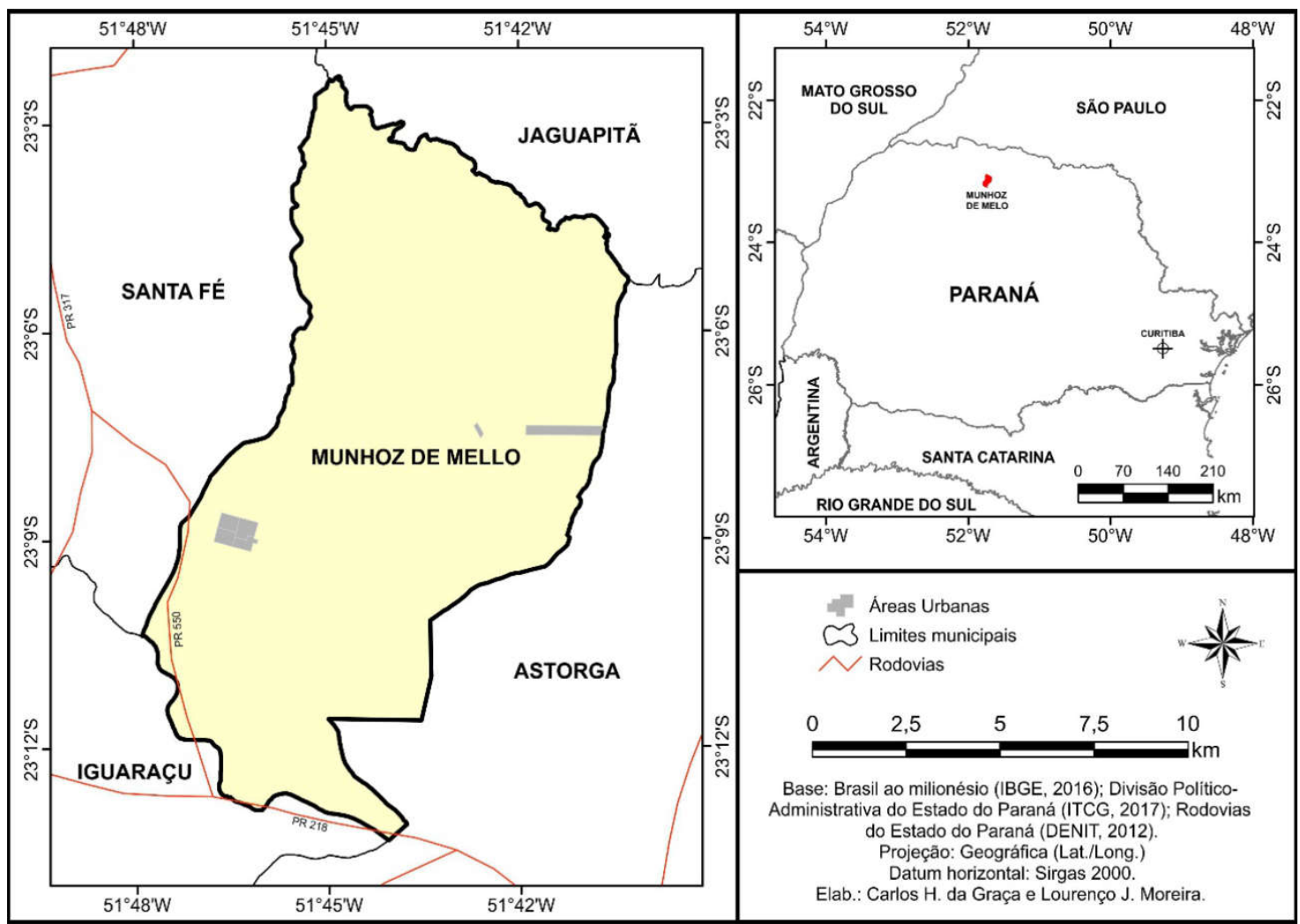

Fonte: Carlos H. da Graça e Lourenço J. Moreira (2018).

A área escolhida para a análise da dinâmica do uso do solo e cobertura vegetal, foi o município de Munhoz de Mello, localizado na região Norte Central 
Paraná, entre as coordenadas geográficas $23^{\circ} 08^{\prime} 52^{\prime \prime}$ de latitude sul e $51^{\circ} 46^{\prime} 26^{\prime \prime}$ de longitude oeste (figura 1), que surgiu como patrimônio da colonizadora Companhia Melhoramentos do Norte do Paraná. O município esteve condicionado ao ciclo do café, no primeiro momento, e aos processos relacionados à erradicação das lavouras de café e de modernização da agricultura, a partir do final da década de 70 do século $\mathrm{XX}$.

Com relação aos aspectos físicos, o clima predominante, segundo a classificação de Nimer e Brandão (1985), é o úmido de tipologias B1 r2, caracterizado por (úmido, Megatérmico, com pouco déficit de água no inverno. (TERASSI e SILVEIRA, 2013, p.122).

A sub-unidade morfoescultural da área de estudo está inserida no Planalto de Maringá, situada no Terceiro Planalto Paranaense, com dissecação baixa; classe de declividade predominante é menor que $6 \%$; em relação ao relevo, apresenta um gradiente de 400 metros com altitudes variando entre 340 (mínima) e 740 (máxima). As formas predominantes são topos alongados e aplainados, vertentes convexas e vales em "V", modeladas em rochas da Formação Serra Geral (MINEROPAR, 2006).

Neste sentido as paisagens do município apresentam pouca variação altimétrica, tendo cotas entre 400 e 500 metros e declividades inferiores a $20 \%$, sendo que nos interflúvios a declividade chega a menos de $8 \%$, fator importante para o estabelecimento e desenvolvimento da agricultura na área de estudo.

Como consequência das características climáticas e geológicas 0 município apresenta em sua estrutura pedológica: Nitossolo Vermelho (textura argilosa), nas baixas vertentes, fundos de vale e proximidade dos córregos e ribeirões; Latossolo Vermelho (textura argilosa), presente nos interflúvios, Argissolo Vermelho (textura arenosa/média) nas médias vertentes e Latossolo Vermelho (textura média) nas áreas de interflúvios. Organossolos ocorrem, ocasionalmente, junto aos rios e em áreas encharcadas.

A formação vegetal natural encontrada é classificada como sendo de remanescentes da Floresta Estacional Semidecidual - Montana e Submontana (PARANÁ, 1987 e IBGE, 2012). Para analisar as mudanças ocorridas na vegetação florestal, foram elaborados mapas de Uso da Terra para os anos de 2006 e 2016, escala de 1:2500, possibilitando observar o aumento do tamanho da cobertura vegetal, reduzindo em algumas áreas 0 isolamento dos fragmentos.

\section{RESULTADOS E DISCUSSÕES}

Com base na análise dos mapas de uso da terra, foi possível evidenciar o aumento das áreas florestadas, localizadas em sua maior parte próximas aos cursos d'água do município. Neste sentido, as figuras 2 e 3 demostram este acréscimo em área, partindo de 301 ha em 2006, correspondendo 2,19\% da área, aumentando para 599 ha em 2016, equivalente $4,36 \%$.

Sobre o uso da terra pela agricultura, observou-se pouca variação no período, demonstrando um pequeno aumento das áreas destinadas a culturas temporárias passando de $67,9 \%$ em 2006 para 68,7\% em 2016. Nas áreas destinadas à pastagem houve uma redução, passando de 29,11\% em 2006, para 25,51\% em 2016 (Tabela 1). O aumento observado na área ocupada pela agricultura temporária, e o baixo percentual das áreas de vegetação florestal, 
se devem sobretudo pelas condições naturais da paisagem do município, especialmente pela baixa classe de declividade do relevo, favorecendo a mecanização. As atividades agropecuárias, juntamente com a silvicultura, ocupam as áreas de interflúvios e médias vertentes.

Neste sentido, pode-se salientar o aumento da área de cobertura florestal passando de 2,1\% em 2006 para 4,3\% em 2016, esta recomposição ocorreu, principalmente nas Áreas de Preservação Permanente, seguindo os córregos localizados na área de estudo, sendo estes afluentes das bacias e sub-bacias dos rios Bandeirante do Norte e Pirapó. Também foram considerados dentro deste percentual os fragmentos florestais localizados a montante da vertente e nos interflúvios.

É importante salientar que a recomposição da cobertura florestal observada nas Áreas de Preservação Permanente e nos demais fragmentos florestais do município, estão relacionados com a atuação dos órgãos ambientais e o cumprimento da Legislação Ambiental. Neste sentido o Estado do Paraná no final da década de 1990, avançou em termos de conservação dos remanescentes florestais por meio de decretos, como o Decreto 387, de 03 de março de 1999, que instituiu o SISLEG - Sistema de Recuperação e Manutenção das Áreas de Reserva Florestal Legal e Áreas de Preservação Permanente.

Essa política ambiental foi de suma importância para a reposição florestal no Estado do Paraná, possibilitando adequação das propriedades rurais quanto a legislação ambiental. Dentre os objetivos, estavam a intenção de reduzir a fragmentação, pois estabeleciam onde deveriam estar as áreas de recomposição, ou mesmo impossibilitar a concentração em uma única área no Estado, perdendo desta forma o papel ecológico que se busca com a recomposição florestal.

Concomitante ao Código Florestal de 1965 (Lei 4.771 de 1965), que ao longo do tempo foi sendo complementado por resoluções, medidas provisórias, - Estado do Paraná, buscou com a Resolução IBAMA/SEMA/IAP n45 de 2007, beneficiar as áreas de Preservação Permanentes localizadas em áreas de várzea, Sociedade Chauá (2008).

Resolução conjunta SEMA/IAP No 005/2009, estabelece e define o mapeamento das áreas estratégicas para a conservação da biodiversidade no Estado do Paraná, priorizando as áreas a serem conservadas e recuperadas, visando a conservação dos recursos hídricos e aumento da conectividade entre os remanescentes florestais.

Com objetivo normatizar as ações relativas a conservação e recuperação do meio ambiente, foi criado pela Lei $N^{\circ} 6.938 / 1981$ o Conselho Nacional do Meio Ambiente - CONAMA, órgão colegiado, de caráter deliberativo e consultivo, com a finalidade de assessorar, estudar e propor ao conselho de Governo e demais órgãos ambientais diretrizes e políticas governamentais para o meio ambiente ecologicamente equilibrado.

Por se tratar de leis que regulamentam as áreas destinadas ao uso e ocupação da terra, as pressões advindas de grupos ligados ao agronegócio e grupos ambientalistas são frequentes. Neste contexto, no ano de 2012, após intensos debates relativos ao Código Florestal, especificamente neste caso, a legislação das Áreas de Preservação Permanente e Reserva Legal, passaram por mudanças a partir do estabelecimento da Lei $n^{\circ} 12.651$ de 25 de maio de 2012. 
Figura 2 - Cobertura Vegetal e Uso da Terra (ano de 2006).

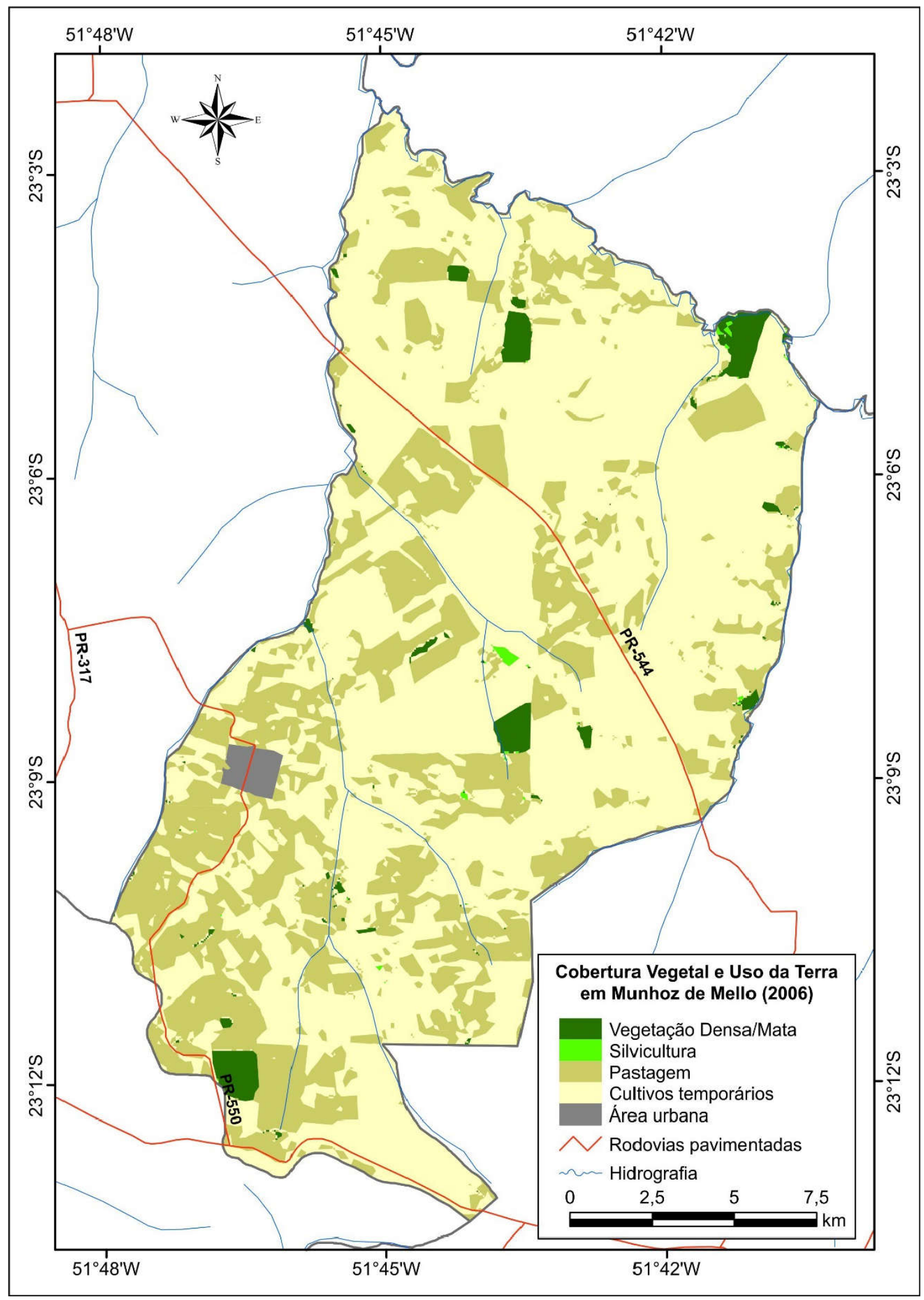


Figura 3 - Cobertura Vegetal e Uso da Terra (ano de 2016).

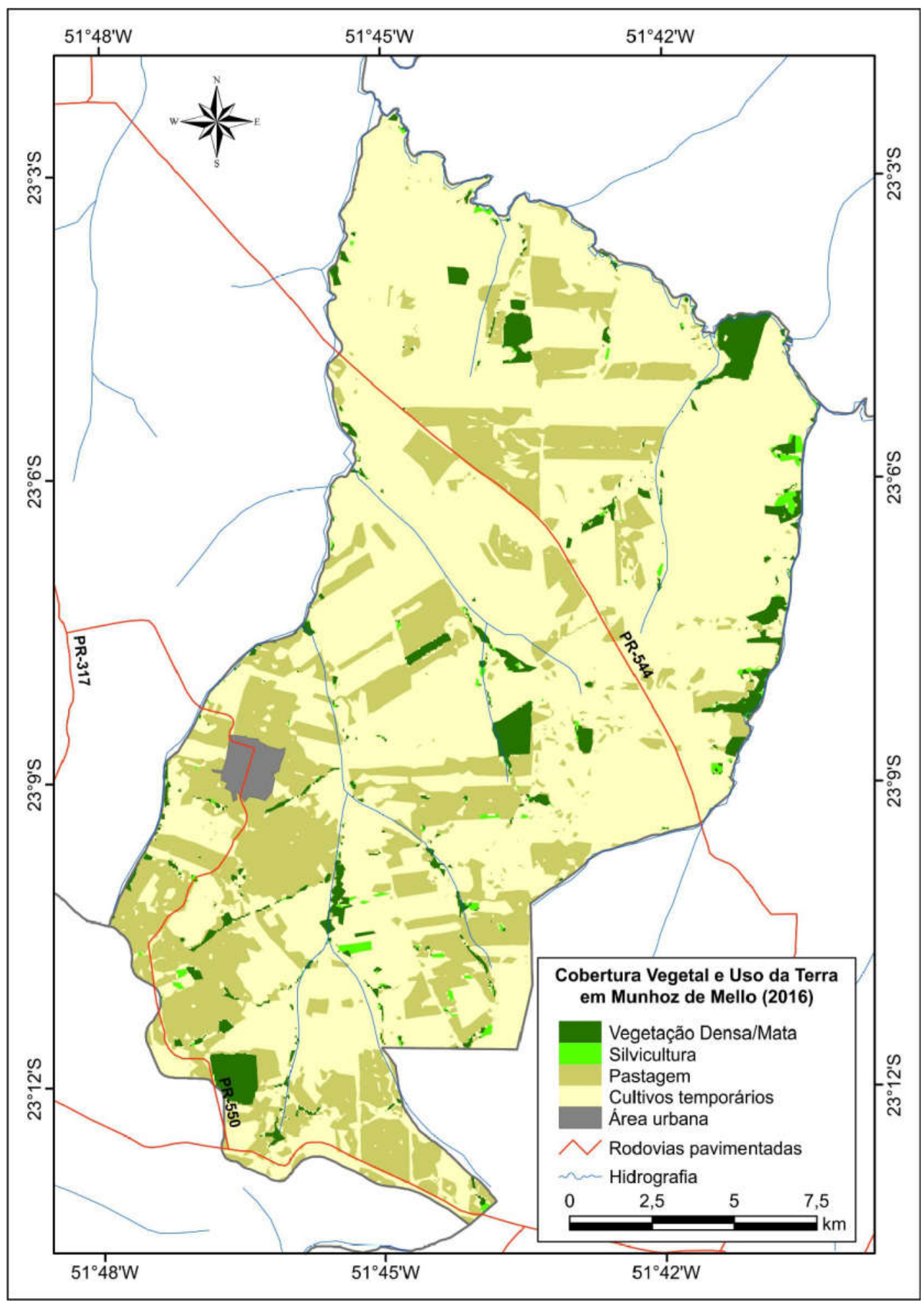


Tabela 1 - Valores em área ocupada pela cobertura vegetal e uso da terra para os anos de 2006 e 2016.

\begin{tabular}{|l|r|r|r|r|}
\multirow{2}{*}{\multicolumn{1}{c|}{ usos }} & \multicolumn{2}{c|}{2006} & \multicolumn{2}{c|}{2016} \\
\cline { 2 - 5 } & \multicolumn{1}{c|}{$\left(\mathrm{km}^{2}\right)$} & \multicolumn{1}{c|}{$(\%)$} & $\left(\mathrm{km}^{2}\right)$ & \multicolumn{1}{c|}{$(\%)$} \\
\hline Cultivos temporários & 93,4719 & 67,97341 & 94,4743 & 68,70232 \\
\hline Pastagem & 40,0257 & 29,10697 & 35,0845 & 25,51368 \\
\hline Vegetação Densa/Mata & 3,01593 & 2,193205 & 5,99459 & 4,359305 \\
\hline Silvicultura & 0,194762 & 0,141632 & 0,967856 & 0,703831 \\
\hline Áreas urbanas & 0,804148 & 0,584782 & 0,991281 & 0,720866 \\
\hline Total & 137,5124 & 100 & 137,5125 & 100 \\
\hline
\end{tabular}

Fonte: Carlos H. da Graça e Lourenço J. Moreira (2018).

A escolha da área como elemento de compreensão da diferenciação da paisagem, bem como sua influência na dinâmica ambiental e socioeconômica, permitiu a compreensão da estrutura da paisagem. Neste sentido os aspectos naturais analisados constituem fatores determinantes no desenvolvimento das atividades econômicas, por se tratar de uma área de uso agrícola; então, fatores como solo e declividade, dentre outros, são fundamentais para o desenvolvimento da agricultura e devem ser avaliados.

Por meio da análise dos mapas de Uso da Terra e Cobertura Vegetal, foi possível observar a distribuição das atividades agrícolas para os anos de 2006 e 2016, constituindo um importante elemento na compreensão da dinâmica de recomposição florestal da área em questão. As alterações nos percentuais de áreas destinadas a agricultura temporária e a pastagem, mostra que essas atividades se estabeleceram e se mantêm nas áreas potencialmente favoráveis e de certa forma se estabilizaram enquanto atividade econômica.

\section{CONSIDERAÇÕES FINAIS}

A partir das análises dos mapas de Cobertura Vegetal e Uso da Terra 2006 e 2016, foi possível avaliar as formas de uso da terra pelas atividades agrícola e pastoril, bem como evidenciar o aumento das áreas de vegetação florestal, fundamentais para o estabelecimento de corredores de biodiversidade e manutenção do equilíbrio dos cursos d'água.

A necessidade de atendimento à legislação que define as áreas de preservação permanente - APP pode ser um dos fatores explicativos desse aumento de área florestada. Para isso devem ser considerados elementos fundamentais para a recomposição florestal, dentre estes as ações legais, regulamentadas pela lei

4.771 de 1965, que estabelecia os princípios legais da preservação das Áreas de Preservação Permanente e Reserva Legal; e atualmente, o novo Código Florestal, Lei $n^{\circ} 12.727 / 12$.

Estes pressupostos legais, juntamente com a fiscalização de órgãos ambientais como o IAP (Instituto Ambiental do Paraná), constituíram elementos fundamentais na recuperação dos fragmentos florestais da área de estudo. 


\section{REFERÊNCIAS}

BRITO, J.L.S.; PRUDENTE, T.D. Análise temporal do uso do solo e cobertura vegetal do município de Uberlândia-MG, utilizando imagens ETM+/Landsat 7. Sociedade \& Natureza, v. 17, n. 32, p. 37-46, 2005b.

FILHO, M. C. A.; MENESES, P. R.; SANO, E. E. Sistema de classificação de uso e cobertura da terra com base na análise de imagens de satélite. Revista Brasileira de Cartografia. $n^{\circ}$ 59/02, agosto 2007.

FLORENZANO, T. G. Imagens de Satélite para Estudos Ambientais. São Paulo: Oficina de Textos, 2002. 97p.

IBGE (Instituto Brasileiro de Geografia e Estatística). Manual técnico da vegetação brasileira: sistema fitogeográfico, inventário das formações florestais e campestres, técnicas e manejo de coleções botânicas, procedimentos para mapeamentos. $2^{\mathrm{a}} \mathrm{ed}$. IBGE - Instituto Brasileiro de Geografia e Estatística, Rio de Janeiro, 2012, 275p.

IBGE (Instituto Brasileiro de Geografia e Estatística). Manual Técnico de Uso da Terra. $3^{\circ}$. ed., Rio de Janeiro: IBGE, 2013.

MINEROPAR. Atlas Geomorfológico do Estado do Paraná. Universidade Federal do Paraná, Curitiba, 2006, 63 p.

PARANÁ. Atlas do Estado do Paraná. Curitiba: Secretaria do Estado da Agricultura e do Abastecimento, Instituto de Terras, Cartografia e Florestas. 1987. 73 p.

PEREIRA, L.H.; PINTO, S.A.F. Utilização de imagens aerofotográficas no mapeamento multitemporal do uso da terra e cobertura vegetal na bacia do rio Corumbataí - SP, com o suporte de sistemas de informações geográficas. Anais... XIII Simpósio Brasileiro de Sensoriamento Remoto. Florianópolis - SC: INPE, 2007.p. 1321-1328

RESENDE, T. M.; REIS, L. N. G.; BRITO, J. L. S.; ROSOLEN, V. Evolução do uso da terra na bacia do Ribeirão Bom Jardim no Triângulo Mineiro/MG. Anais XV Simpósio Brasileiro de Sensoriamento Remoto - SBSR, Curitiba, PR, Brasil, 30 de abril a 05 de maio de 2011, INPE p.6955.

RIBEIRO, V. H.; GONÇALVES, J. F. A.; PAIVA, R. G. Transformações da paisagem rural da microrregião de Paranavaí - PR e a expansão da cana-de-açúcar nos municípios de Tamboara e Itaúna do Sul de 1970-2012. Revista Percurso, 5:55-86. (2013)

SOCIEDADE CHAUÁ. Plano de Manejo da Reserva Nhandara Guaricana São José dos Pinhais. Curitiba: Sociedade Chauá/ SPVS, relatório técnico, 2008.

TERASSI, P. M. B.; SILVEIRA. Aplicação de sistemas de classificação climática para a bacia hidrográfica do rio Pirapó-PR. Revista Formação, v.1, n.20, p.111-128, 2013. 